\title{
Between combine harvester and ribosome
}

\author{
An Agricultural Research Council/ \\ Medical Research Council commit- \\ tee has recently produced a report \\ on food and nutrition research. John \\ Rivers of the Nuffield Institute of \\ Comparative Medicine, London ex- \\ amines its significance.
}

Periodically, action by government committees and individuals in this country has resulted in the science of nutrition being rescued from its characteristic doldrums and becoming a national priority. A government inquiry into the physique of recruits for the Boer War got the subject moving in the first place, and later action by people like Lord Boyd-Orr and Sir Jack Drummond gave a new impetus to its growth. These efforts were successful not least because of the military importance of a healthy population. Since 1945, nutrition in the UK has been neither of military importance nor Nobel Prize ranking. It has lost much Research Council support and the standard of the subject and its workers has declined.

The report* of the committee under Professor A. Neuberger is the latest attempt to enumerate nutritional priorities and halt that decline. It examines not only the nutritional status of Britain, but the state of our nutritional knowledge and recommends guidelines for the development of the subject until the end of the century. The strategy adopted is praiseworthy. Priority, it is argued, must be given to "areas of special importance or urgency". Three such are identified-the maintenance and safety of our food supply, the role of nutrition in diseases of complex or uncertain origin, and the extension of our knowledge of the metabolism of nutrients.

Professor Neuberger's committee were asked to prepare a report for both the Agricultural Research Council (ARC) and the Medical Research Council (MRC), an event which is in itself a milestone. The secretaries of the councils weloome it "as a basis for discussion both within the councils and in the wider scientific community preparatory to the consideration of policy". So far the wider scientific community seems, publicly at least, to have been somewhat muted in its discussion. There is therefore the real

*Food and Nutrition Research, (HMSO $£ 3.80$ ). possibility that the Neuberger report could, without challenge, become the policy document. This would be a pity, because, despite all its outstanding qualities, the report is a markedly flawed document. The committee has managed to outline graphically some of the priorities of nutrition, but they have remained oblivious of others. The net result is a report which could set back the overall subject by 25 years.

The bulk of the report is a detailed summary of the present state of knowledge in nutrition. Since something over a gross of experts have been consulted, this makes breathtaking reading. If it were expanded and in parts rewritten it would become a necessary primer in nutrition but, as it is now, its function is obscure. It is too condensed to serve as a text book, it is unreferenced and so of little use as a source book, and it is too high powered to be of use as a guide to civil servants working for the research councils or to trustees of foundations. If it is merely there to impress, it succeeds. Moreover it does so in a way that eloquently illustrates Professor Neuberger's conviction that "the answers to many of the most difficult problems in nutrition are ultimately to be found at the molecular or cellular level of biological organisation".

Sir Harold Himsworth-formerly Secretary of the MRC--held a comparable opinion, and some nutritionists felt then that this was a sadly mistaken and reactionary view. Probably they are even sadder now that Professor Neuberger has revived it. Both Himsworth and Neuberger may have described what the MRC choose to fund, but they are not discussing nutrition. In fact they are describing just what nutrition is not. The subject falls somewhere between the combine harvester and the ribosome, but it is not agricultural engineering nor is it molecular biology. It may draw from both but is identical with neither, and it is to be hoped that research councils are aware of its limits when considering which "nutrition projects" to support.

Human nutrition is about the interaction of Man, men and food. It is both a social and a biological science, the domain of generalists who may have some special expertise but remain generalists. Those answers which can only be found at the molecular level, or indeed the economic level, are answers to problems in molecular biology or economics. Both are im- portant and both should receive funding, but not with money designated for nutrition research.

The apparent erudition of the Neuberger report tempts one, however, to accept the committee's view. The complexity of its science makes it difficult to argue with its insight. Jehovah's Witnesses quate the Bible for much the same effect, but fortunately Professor Neuberger's sources are neither as infallible nor as all-embracing. The result is a review which is eclectic, not exhaustive. Muoh of what it says is exciting but what it omits is terrifying. Seventy-five pages, for example, are devoted to physiology and biochemistry but only one to ways of influencing food consumption patterns. Even the stress given to different metabolic problems is difficult to understand, unless the length of the contribution is proportional to the status of the author. So although protein and energy metabolism are elegantly viewed from every angle, and coordinated proposals for research in metabolic aspects of obesity advanced, subjects like sucrose and essential fatty acids (EFA) are hardly mentioned.

Yet sucrose provides $15 \%$ of the energy of a UK diet-which is a higher fraction than protein supplies. This is a level of consumption which alarms many nutritionists and can delight nobody except the British Sugar Bureau. For some reason the nutrition establishment in the UK seems to regard neither sucrose nor EFA as respectable areas of nutritional research. Perhaps that is the reason why the 27 lines that are devoted to EFA and prostaglandins are so poor. They are marred by misleading omissions, by an erroneous summary of the evidence relating to human requirements and the idiosyncratic phrase "membranes of structural lipids". But the committee's incorrect assertions that "all prostaglandins are metabolically derived from arachidonic acid" or that " $\gamma$-lindenic acid is the immediate precursor of arachidonic acid" make the review not only superficial but worthless.

Similar problems occur elsewhere, so that the overall impression is of a report biased in its summary of the literature. Every scientific review is, of course, similarly biased, but since this one gives no references it is impossible to tell whether the author or the reader is ignorant of the literature. Would an unbiased reader really 
conclude that studies on high doses of vitamin $\mathrm{C}$ have resulted in "very little sound evidence" that it can have any beneficial effect and "some reason to suspect it may be harmful"? Or would he remain open minded?

But the scientific review is only the sprat. The mackerel is the set of policy proposals found, in the main, as terse sentences interspersed with the reviews, and designed to give practical expression to Neuberger's three priorities.

Not one of these can be objected to; they are all worth investigation. But then, given enough time and money, so is Uri Geller. If the proposals are considered as the expression of priorities in nutrition many must be rejected. They are the thoughts of experts enthusing over past triumphs and the importance of what they wish to do next. Such enthusiasm is of importance in science, but its expression in this report is sufficiently uncontrolled that a fusillade of ideas have scattered like buckshot around the target. Although Professor Neuberger has sometimes given due priority to an outstanding research need-for example the whole subject of protein and energy metabolism-he has done a disservice by failing to regard any aspect of metabolism as less than a priority.

The committee's approach to the use of animal models also seems to lack coordination. Such models are lacking for many of the intractable problems of nutrition, and the common laboratory species are perversely disinclined to suffer from obesity, diabetes mellitus, kwashiorkor, ischaemic heart disease and many of the other great nutritional scourges. Which is probably why the diseases remain; if the guinea pig possessed L-gulanolactone oxidase, scurvy might pose quite formidable research problems. Primates are proposed at a number of points as a useful model and the limited usefulness of other animals mentioned.

In their views on primates the committee holds an Aristotelian view of animal relationships as a scala nuturae. This is a view that has been criticised elsewhere with the admonition to choose the model for its particular functional similarity to man rather than on the basis of some vague evolutionary notion of affinity.

There is a case to be made for giving priority to comparative nutrition if we are ever to understand human nutritional disease. Interspecific generalisations like the relationship between energy expenditure and body weight can only improve our perspective on man. When the similarities are established even the species differences can be valuable. If, as the committee suggest, a considerable proportion of basal metabolic rate is accounted for by the energy cost of protein turnover, how does the cat have a normal energy requirement but a protein requirement twice the interspecific mean?

But above all a comparative approach might teach us to look at animals, their diets and their diseases as an ecological whole. Nutritional epizootology could do much to counteract the myopia of nutritional epidemio$\log y$.

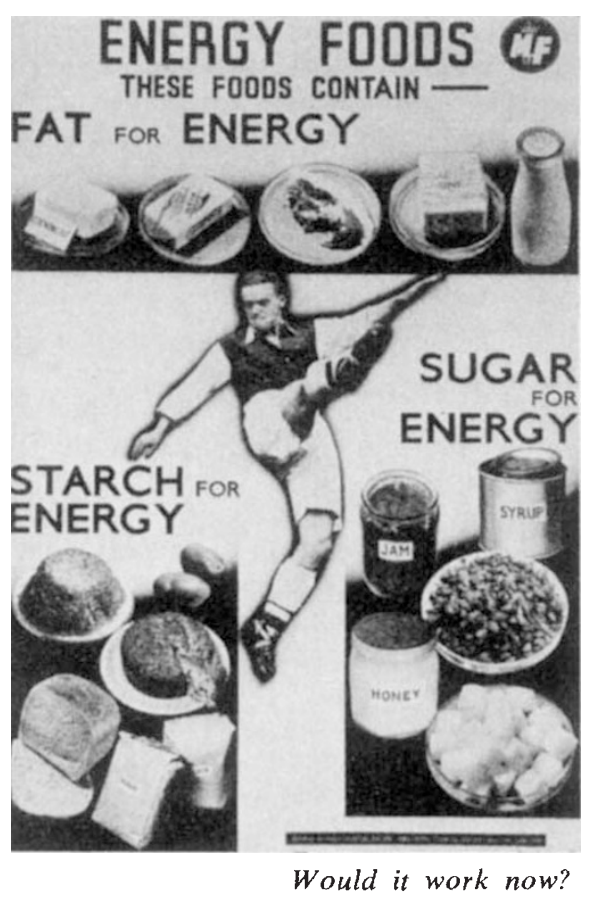

Myopic, too, is the only way to describe the neglect shown by the Neuberger committee of the whole subject of social nutrition. Precious little value is placed on studies of what people eat-and virtually none on the important field of why they eat it, and why they do not. How do we persuade a person to eat what we regard as good, and avoid what we regard as harmful? No amount of heavyweight basic science in nutrition can avoid the fact that food that is not eaten has no nutritional value. Nor can any amount of enthusiasm about action at the molecular level avoid the responsibility of the nutritionists to improve human diets. That responsibility is all too often not discharged because neither nutritionists or physicians know how to alter effectively what people eat.

The omission of any discussion on social nutrition is a curiously blinkered attitude. If it was an error it will no doubt be as unfortunate as it is inexplicable. What young research worker of 'potential' will be attracted now into social nutrition? The subject, anyway, is discouraging - the experiments are often equivocal and research funds are scarce. Presumably funds will now dry up altogether.

It is a pity that Neuberger did not see fit to review the classic work of Barker, Bannicott, Burnett, Douglas,
Joy and Yudkin, or any of the other authors who seem to be aware that food is something more than the sum of its nutrients. If consulted, their views on priorities would have been something more than a lame note on how "it would be of considerable interest to review the results of advertising campaigns... and to assess the effect of these on the nutritional value of the diet". We do not know with any precision why or how the UK diet is changing. We do not know why nutrition education fails when advertising works.

Nutritionists are not in business to pursue uncluttered academic research but to improve the nutritional status of the population. Yet they don't know how except by draconian war-time rationing. Meanwhile the pragmatic, arcane arts of the advertising industry are being neither studied nor tested by the academic world.

In the developing world, our knowledge is even more limited. Although nutrition education has proved ineffective as a method of achieving dietary change in the UK it still flourishes as the panacea for Africa's ills. Only recently has there been any serious attempts to see if it works and why it fails. Even now the analyses are oversimplified-for example, no serious attempts are made to identify socioeconomic behaviour. Africans are lumped together, or at best split into tribes and nations.

No less urgent is our need to study the sociology of nutritional science. Some field nutritionists have felt that, despite their best efforts, their role as an alien expert inevitably has an overture of racial arrogance. At its worst this is a caricature: the western bourgeois explaining to an African lady how she should prepare one of her own traditional recipes. But even at its least offensive it remainswestern man and his science in judgement on another culture and its beliefs. Western man cannot even claim always to have been correct. The life and death of the protein myth, and the distorting effect it has had not only on aid but on the overall development of nutritional science, needs not merely comment but a detailed critical analysis. If we wish to change nutrition, we must understand its structure.

There are two views about the 'golden age' of nutrition. Many, scientists feel that this was the vitamin era before the war, when nutrition and biochemistry were synonymous. But to the public it was of most use during the Seoond World War, when the state of nutrition of the nation improved. It is with use that one must be concerned, and if practical nutrition were given as high a priority as basic science, its 'golden age' could yet be to come. 